\title{
EXPERIMENTAL VERIFICATION OF IMPREGNATED TEXTILE REINFORCEMENT SPLICING BY OVERLAPPING
}

\author{
TOMÁŠ Vlach ${ }^{a, b, *}$, LenkA Laiblováa, JaKUB ŘePKA ${ }^{a, b}$, \\ Zuzana Jirkalová ${ }^{b}$, Petr HáJeK ${ }^{a}$ \\ ${ }^{a}$ Czech Technical University in Prague, Faculty of Civil Engineering, Department of Building Structures, \\ Thákurova 7, 16629 Prague, Czech Republic \\ ${ }^{b}$ Czech Technical University in Prague, University Centre for Energy Efficient Buildings, Třinecká 1024, 27343 \\ Buštěhrad, Czech Republic \\ * corresponding author: tomas.vlach@cvut.cz
}

\begin{abstract}
This paper presents an experimental verification of impregnated textile reinforcement splicing by overlapping using tensile test of small textile reinforced concrete slabs before its using in the product. The specimen dimensions were designed $80 \times 360 \mathrm{~mm}$ and thickness approximately $18 \mathrm{~mm}$. This specimen was reinforced using two pieces of impregnated flat technical fabric from carbon roving and epoxy resin. Two overlap lengths were designed using data from previous cohesion tensile tests and necessary anchoring length. The purpose of this experiment was experimental verification before flat reinforcement splicing by overlapping on the final product - furniture with textile reinforcement. This paper shows possible problems and complications in the anchoring of the textile reinforcements and in splicing by overlapping, the importance of the accuracy reinforcement position in the thin concrete cross-sectional area.
\end{abstract}

KEYWORDS: Textile reinforcement, high performance concrete, textile reinforced concrete, reinforcement splicing, reinforcement overlapping.

\section{INTRODUCTION}

Textile reinforced concrete (TRC) [1, 2] is new modern composite material made from high performance concrete (HPC) 3 reinforced by technical fabrics. For new structures are often used impregnated composite fabrics by epoxy resin and other materials because of stabilization and also technology of concreting in comparison with non-impregnated. Non-impregnated fabrics are often used for strengthening of reinforced concrete (RC) structures. Carbon fabrics used in this experiment were impregnated and stabilized by epoxy resin. It was selected impregnated fabrics commonly available on the market and own developed recipe of HPC. These both TRC materials are mechanically resistant, chemically resistant and corrosion free. Since the component thickness for $\mathrm{RC}$ walls, facade panels and other elements is normally only determined in order to satisfy the concrete cover corrosion protection required in Eurocode 2, exterior construction elements must be designed with a thickness $80 \mathrm{~mm}$ and even higher. Thanks to the noncorrosive new reinforcement elements can be made thinner. The concrete cover must be designed only for transferring of bonding stresses between the concrete and textile reinforcement and it is approximately $10 \mathrm{~mm}$. So the building TRC elements can be approximately $30 \mathrm{~mm}$ thick with two layers of textile reinforcement. Concrete cover for TRC specimens is designed only with regard to the transfer of forces. In particular, the basic strength properties of both materials and interaction condi- tions between technical fabric and HPC are studied using most often using tensile test [4. Tensile test was selected also for presented verification of splicing by overlapping. Interaction conditions and bond behavior goes hand in hand with anchoring length and also with reinforcement splicing. Many studies, models and experiments was already done [5] 8 also at CTU in Prague in previous research for example [9-11]. This paper presents experimental verification of impregnated textile reinforcement splicing by overlapping using small TRC specimens before its using in the final products. These products can be for example footbridges constructions, concrete furniture and facade elements with larger dimensions and different shapes, where the joining of textile reinforcement is necessary.

\section{MATERIALS USED IN EXPERIMENT}

\subsection{CONCRETE}

The HPC mixture used in this experiment was developed and optimized in last years at the CTU in Prague for different applications. Concrete recipe is presented in Table 1 It is the self-consolidating fine grain concrete without any fibres. Materials used for experiment are primarily from local sources and components are: CEM I $42.5 \mathrm{R}$ cement, silica sand with two particle sizes and maximum grain size $1.2 \mathrm{~mm}$, silica flour with one particle size, microsilica and one type of the PCE superplasticizer. Developed mixture reduces the amount of water on water/cement 


\begin{tabular}{lr}
\hline mix content & $\mathrm{kg} / \mathrm{m}^{3}$ \\
\hline cement I 42.5 R & 680 \\
technical silica sand & 960 \\
silica flour (ground quartz) & 325 \\
silica fume (microsilica) & 175 \\
superplasticizers & 29 \\
water & 171 \\
total & 2340 \\
\hline
\end{tabular}

TABLE 1. HPC mix composition.

ratio only 0.25 and therefore significantly improves the mechanical properties.

Direct tensile strength of used HPC is experimentally determined to $5.0 \mathrm{MPa}$ respected the CSN 731318 standard. Tensile strength in bending is $16.8 \mathrm{MPa}$ on prisms $40 \times 40 \times 160 \mathrm{~mm}$ with distance between supports $100 \mathrm{~mm}$ according to CSN EN 123905 standard. Compressive strength is $106 \mathrm{MPa}$ on $100 \mathrm{~mm}$ cubes according to CSN EN 12390-3 standard. Static modulus of elasticity is $49.2 \mathrm{GPa}$ on prisms $100 \times 100 \times 400 \mathrm{~mm}$ according to CSN ISO 1920-10 standard [12].

\subsection{ReINFORCEMENT}

For presented experiment was used commonly available flat composite concrete reinforcement produced by @Solidian company. Technical fabrics were made of carbon fibre roving and stabilized and impregnated by epoxy resin. Flat textile had dimensions $5 \times 1.2 \mathrm{~m}$ and was cut to the required specimens dimensions. Grid spacing was $21 \mathrm{~mm}$ for both longitudinal and lateral directions. Basic parameters of used carbon roving are: Cross section area of the strands $1.81 \mathrm{~mm}^{2}$, tensile strength of fibrils more than $4000 \mathrm{MPa}$. Basic parameters of impregnated reinforcement: Cross section area of the reinforcement $85 \mathrm{~mm}^{2} / \mathrm{m}$ for both directions, tensile strength $3300 \mathrm{MPa}$ (characteristic value $2500 \mathrm{MPa}$ ) and Youngs modulus more than $220 \mathrm{GPa}$. Other information and parameters of reinforcement are mentioned in the technical data sheet.

\section{EXPERIMENTAL INVESTIGATION}

Concreting of specimens with dimensions $80 \times 360 \times$ $18 \mathrm{~mm}$ was done in two layers with the reinforcement applied in the middle of specimens. The casting process was done without any use of spacers. This procedure ensured concrete cover approximately $7 \mathrm{~mm}$ for both surfaces. Only one layer of technical fabric with two pieces were used as a reinforcement with 4 rovings in longitudinal direction. View on the reinforcement just before concreting is presented in Fig. 1. Two groups of three specimens were prepared with minimal length of fabrics overlapping approximately 35 and $55 \mathrm{~mm}$ based on the previous calculations of anchoring length approximately $30 \mathrm{~mm} \mathrm{[7,} \mathrm{9].} \mathrm{It} \mathrm{means} \mathrm{a} \mathrm{dis-}$ tance of one or two meshes spacing plus free overlap of cut reinforcement. One both ends of specimens were fabrics doubled using small piece of composite reinforcement as a protection against specimen damage on the ends during the experiment and its possible negative effect on achieved results.

Uniaxial tensile test was chosen for the testing procedure of splicing by overlapping because it is the clearest experimental verification of reinforcement connection. In the middle of the specimens were created a small transverse notch approximately $1.0 \mathrm{~mm}$ deep on both specimen sides so that the first tensile crack was initiated just in the middle of the monitored specimen part. Both end of TRC specimens were fixed between two steel plates with thickness $5 \mathrm{~mm}$ using four screws in combination with chemical mortar on the entire contact area. The fitted length was $100 \mathrm{~mm}$ for both ends, so free monitored length for testing was $160 \mathrm{~mm}$. Using fifth screw on the end of steel plates simulated the joint and small next top steel plate were specimens fixed in the testing machine. Tensile test was performed in MTS 100 testing machine with controlled load speed $2.0 \mathrm{~mm}$ per minute after 28 days of specimens hardening. In Fig. 2 is presented the testing scheme with all dimensions. The loading process continued until the sample failure with constant load speed. Measured values were force, time and displacement.

\section{EXPERIMENTAL RESUltS PRESENTATION AND DISCUSSION}

Results of experimental verification are presented in graph in Fig. 3. The form of presented graph is force on $\mathrm{y}$ axis and displacement on $\mathrm{x}$ axis. One typical experimental curve for both group of three specimens is presented. It can be easily calculated the maximal theoretical tensile force $29.0 \mathrm{kN}$ in the moment of reinforcement failure [13]. Maximal characteristic tensile force $17.9 \mathrm{kN}$ was calculated using characteristic value of tensile strength and composite reinforcement cross sectional area. The maximal force reached in experiment was $12.6 \mathrm{kN}$ only for overlap $55 \mathrm{~mm}$ and the failure was always in the concrete part of reinforcement contact.

The beginning of the curve and loading process was irregular until a deformation of about $0.3 \mathrm{~mm}$ when the sample position was stabilized in the testing machine. The linear part than followed when the concrete part is not cracked until the moment of the first crack initiation. The drop in force after the moment of the first crack initiation is minimal and it means that the carbon composite flat reinforcement was very quickly activated. Next part of oscillated curve is called multiple cracking zone, which is nonlinear and represent the process of reinforcement full activation in its length. Next zone without larger curve oscillation and it is called post-cracking behavior [14. But in Fig. 3 this part of curve is visible only for specimen with $2 \mathrm{x}$ spacing. It means a distance of two meshes spacing plus free overlap of cut reinforcement, so spacing approximately $55 \mathrm{~mm}$. The part of curve 


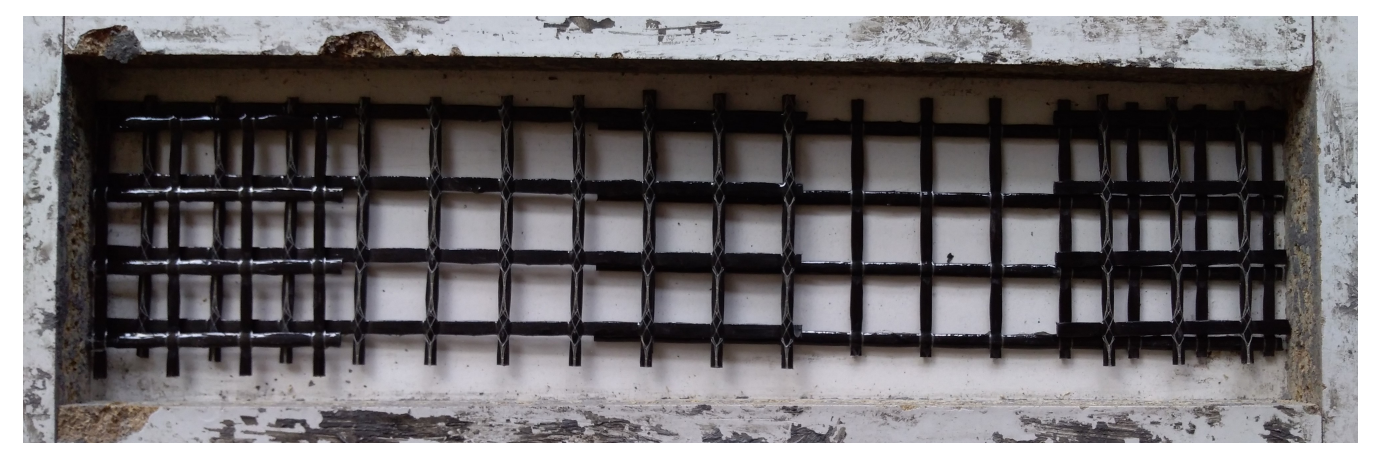

Figure 1. View in the wooden mold just before casting process on the used flat carbon concrete reinforcement with overlapping in the middle part.

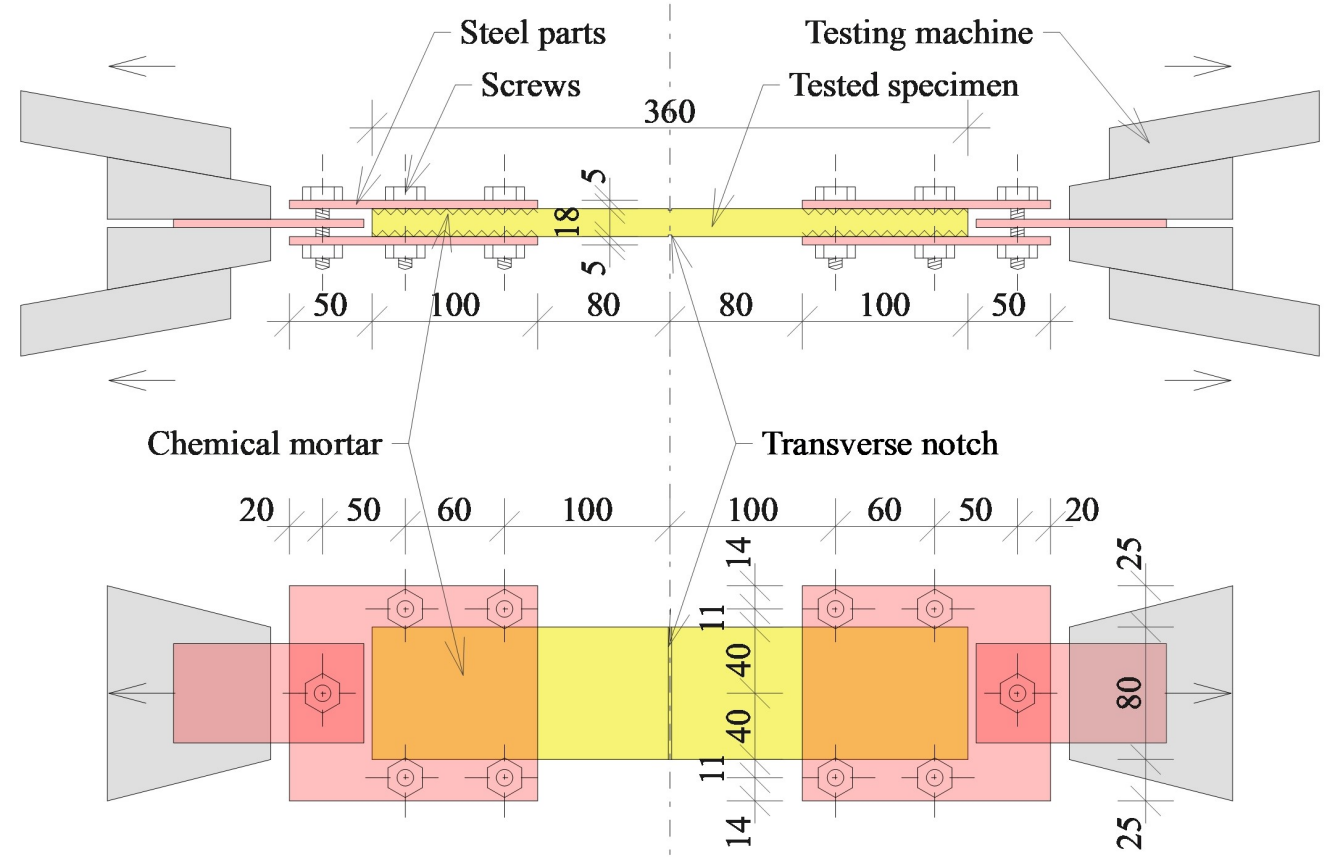

Figure 2. Scheme of the testing set up with dimensions.

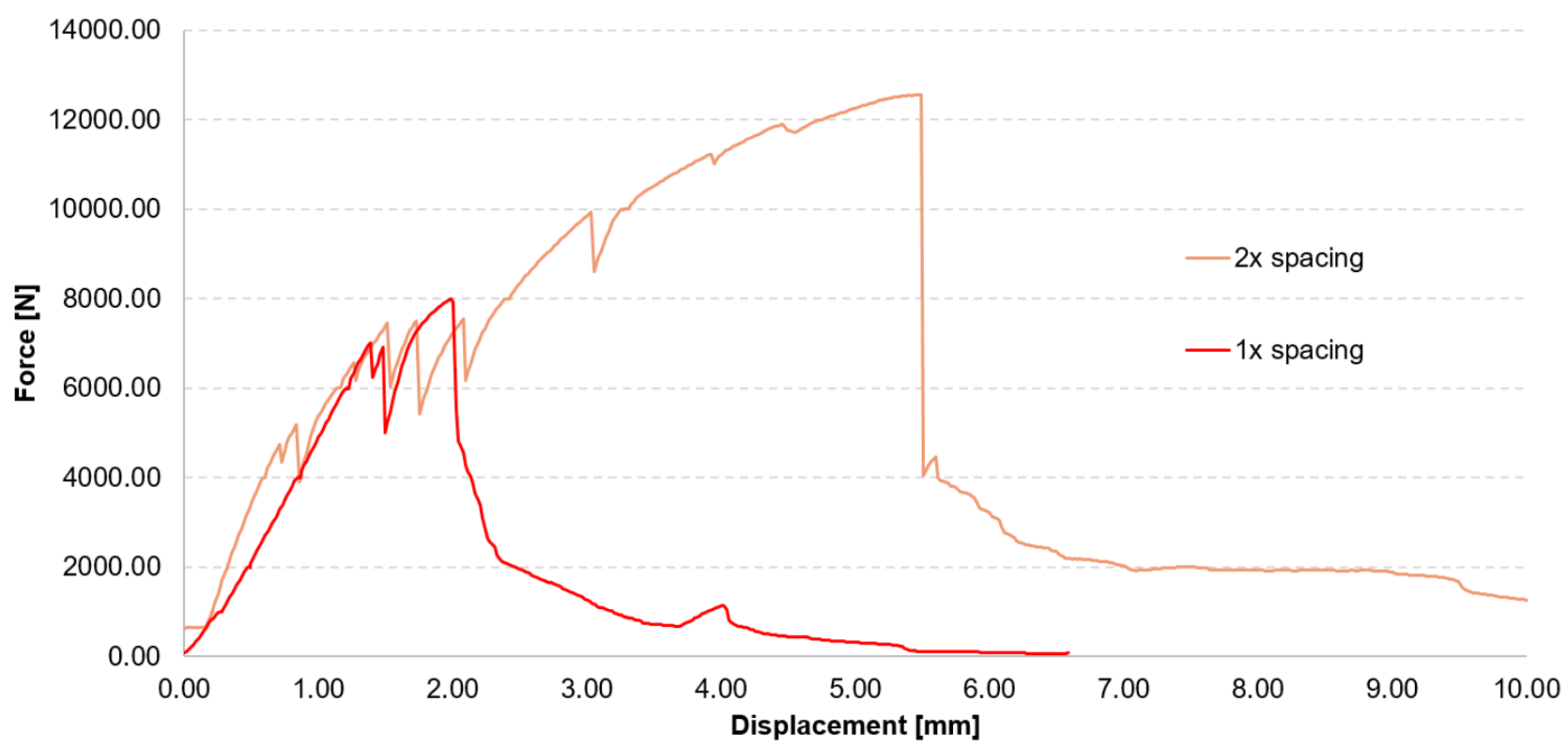

Figure 3. Test results presented in the form of force - displacement graph. One typical experimental curve for both groups is presented. 

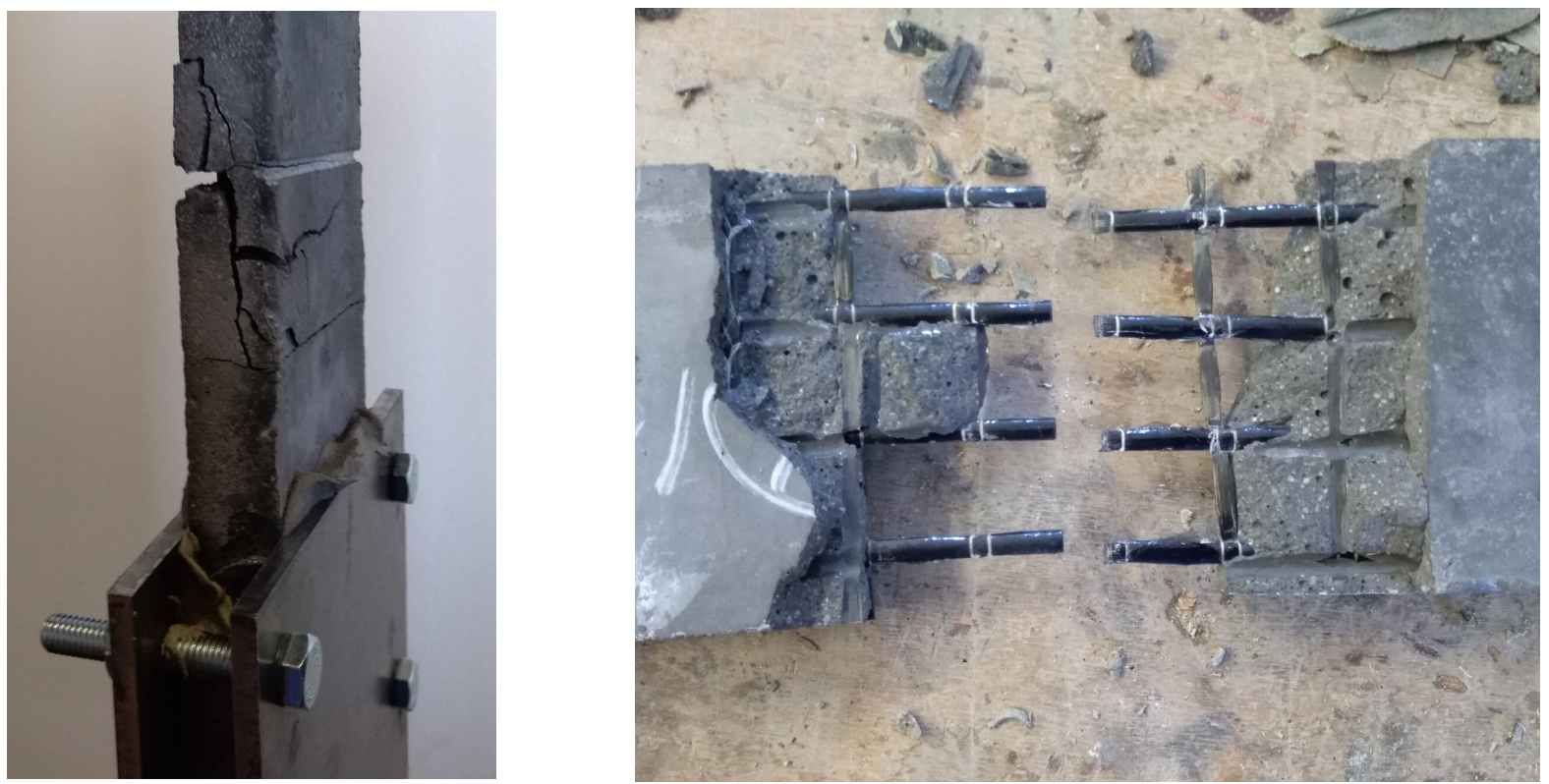

FiguRE 4. Typical detailed pictures of damaged specimens with shear collapse during testing procedure and just after the collapse of specimens and its uninstalling from the testing machine.

was no longer as expected from the numerical nonlinear model, because the damage occurred in concrete contact part, not in reinforcement.

In Fig. 4 is presented the typical shape of crack in the moment during the loading process when both reinforcement layers are separated from each other. Before this collapse point on all specimens were visible multiple cracking. On the right part of same Fig. 4 is presented the view on the damaged both halves of specimen after the loading process and its uninstalling from the testing machine. One of the halves was logically turned upside down in comparison with the position in the testing machine so both broken areas are visible. Also the bond behavior of composite reinforcement without surface treatment was lover as visible in Fig. 4 on the right part. The interaction of reinforcement was caused more or less due to the small shapes of the reinforcement in its longitudinal direction due to the technological progress of the mesh production. The surface of the reinforcement was otherwise smooth [12]. It leads to the need for a larger concrete cover of the flat reinforcement for bonding stresses transferring between the concrete part and reinforcement or necessary reduction of cross sectional carbon roving area. After the samples examination it was found that the expected position of composite reinforcement in cross-sectional concrete area was not assured. Overlapped reinforcement layers were sometimes more than $4 \mathrm{~mm}$ apart from each other. This resulted in high eccentricity and additional stresses as well as significant reduction of the cover layer of the reinforcement. It was not included in the previous numerical model. The position of the reinforcement in the cross sectional concrete area must be precisely determined for the future applications.

\section{Conclusions}

This article presents experimental results of TRC tensile test with splicing of technical textiles by overlapping. In the curve is visible the multiple cracking until the moment of maximal stress before the failure in the contact area of reinforced meshes. The real distance between textiles axis were approximately $4 \mathrm{~mm}$ and higher. It was more than excepted values in previous numerical model because the yarn thickness was less than $1.0 \mathrm{~mm}$. It led to the higher eccentricity and higher additional negative stresses initiation in the cross-section of overlapped reinforcement part. During the loading test for all tested samples reinforcement layers were separated from each other in the concrete part without any damage of reinforcement in longitudinal direction. This experiment presents the importance of all details during designing and realization of TRC applications. With extremely small thicknesses of constructions and small concrete cover also small millimetre details and deviations from the assumption can very negatively affected final results. It is very important to ensure the precise position of the composite reinforced fabrics in cross-sectional concrete area for example using small plastic spacers and splicing area should be fixed due to the unwanted eccentricity in the tensile load. Also longer anchoring length should be designed for safety load transfer through the reinforcement contact.

\section{ACKNOWLEDGEMENTS}

This particular outcome has been achieved with the financial support of the TACR 11124311 3111702A124Subtle Concrete Furniture and Small Structures for the Railways Stations, it has been supported by the Ministry of Education, Youth and Sports within National Sustainability Programme I, project No. LO1605 and also 
by SGS18/108/OHK1/2T/11 - Environmental aspects of high performance cement composites and concrete with recycled aggregate including their durability and service life. The authors would like to acknowledge all the financial help that was provided in order to support this original research.

\section{REFERENCES}

[1] W. Brameshuber (ed.). Report rep036 : Textile Reinforced Concrete - State-of-the-Art Report of RILEM TC 201-TRC. RILEM Publications SARL, 2006.

[2] T. Bittner, P. Bouška, M. Kostelecká, M. Vokáč. Experimental investigation of mechanical properties of textile glass reinforcement. Applied Mechanics and Materials 732:45-48, 2015.

[3] P. Reiterman, M. Jogl, V. Baumelt, J. Seifrt. Development and mix design of HPC and UHPFRC. In Mechanical, Thermal and Hygric Properties of Buildings Materials, vol. 982 of Advanced Materials Research, pp. 130-135. Trans Tech Publications, 2014. DOI:10.4028/www.scientific.net/AMR.982.130.

[4] J. Hartig, F. Jesse, K. Schicktanz, U. Häußler-Combe. Influence of experimental setups on the apparent uniaxial tensile load-bearing capacity of textile reinforced concrete specimens. Materials and structures 45(3):433-446, 2012.

[5] J. Hartig, U. Häußler-Combe, K. Schicktanz. Influence of bond properties on the tensile behaviour of textile reinforced concrete. Cement and concrete composites 30(10):898-906, 2008.

[6] E. Lorenz, R. Ortlepp. Bond behavior of textile reinforcements - development of a pull-out test and modeling of the respective bond versus slip relation. In High Performance Fiber Reinforced Cement Composites 6, pp. 479-486. Springer, 2012.

[7] S. Xu, H. Li. Bond properties and experimental methods of textile reinforced concrete. Editorial Department of Journal of Wuhan University of Technology - Materials Science Edition 22(3):529-532, 2007.
[8] R. Chudoba, M. Vořechovskỳ, M. Konrad. Stochastic modeling of multi-filament yarns. I. Random properties within the cross-section and size effect. International Journal of Solids and Structures 43(3-4):413-434, 2006.

[9] T. Vlach, M. Novotná, C. Fiala, et al. Cohesion of composite reinforcement produced from rovings with high performance concrete. Applied Mechanics and Materials 732:397-402, 2015.

[10] T. Vlach, A. Chira, L. Laiblová, et al. Numerical simulation of cohesion influence of textile reinforcement on bending performance of plates prepared from high performance concrete (HPC). In Proceedings from 21st Czech Concrete Day 2014, vol. 1106 of Advanced Materials Research, pp. 69-72. Trans Tech Publications, 2015. DOI:10.4028/www.scientific.net/AMR.1106.69.

[11] O. Holčapek, F. Vogel. Bond properties of concrete beams strengthened by AR-glass textile and basalt textile reinforced concrete. Applied Mechanics and Materials 825:7-10, 2016. DOI:10.4028/www.scientific.net/AMM.825.7

[12] T. Vlach, L. Laiblová, M. Ženíšek, et al. The effect of surface treatments of textile reinforcement on mechanical parameters of HPC facade elements. In Special Concrete and Composites 2015, vol. 677 of Key Engineering Materials, pp. 203-206. Trans Tech Publications, 2016. DOI:10.4028/www.scientific.net/KEM.677.203

[13] Comparison of Different Methods for Determination of Modulus of Elasticity of Composite Reinforcement Produced from Roving, vol. 1054 of Advanced Materials Research. Trans Tech Publications, 2014. DOI:10.4028/www.scientific.net/AMR.1054.104.

[14] R. Contamine, A. Si Larbi, P. Hamelin. Contribution to direct tensile testing of textile reinforced concrete (TRC) composites. Materials Science and Engineering A-structural Materials Properties Microstructure and Processing 528:8589-8598, 2011. DOI:10.1016/j.msea.2011.08.009. 